\title{
Occupational stress of employees in an insurance company
}

\author{
W.J. Coetzer and S. Rothmann* \\ WorkWell, Research Unit for People, Policy and Performance \\ North-West University, Potchefstroom Campus, Private Bag X6001, \\ Potchefstroom 2520, Republic of South Africa \\ bpksr@puk.ac.za
}

Received March 2002

\begin{abstract}
The objectives of this study were to assess the internal consistency of the ASSET, to identify occupational stressors for employees in an insurance company and to assess the relationships between occupational stress, ill health and organisational commitment. A cross-sectional survey design was used. An availability sample $(N=613)$ of employees in an insurance company was used. An Organisational Stress Screening Tool (ASSET) was used as measuring instrument. The results showed that job insecurity as well as pay and benefits were the highest stressors in the insurance industry. Two stressors, namely job characteristics and control were statistically significant predictors of low organisational commitment. Physical ill health was best predicted by overload and job characteristics. Three stressors, namely work-life balance, overload and job characteristics best predicted psychological ill health.
\end{abstract}

*To whom all correspondence should be addressed.

\section{Introduction}

Due to rapid economic growth, urbanisation and popular education (Chan, 2002) the insurance industry expanded considerably in the $19^{\text {th }}$ century, resulting in acute competitiveness and rivalry between companies (Chan, 2002; Lai, Chan, Ko \& Boey, 2000). The impact of this competitiveness is felt amongst employees in the insurance industry by engendering general feelings of distrust, tension, strain in interpersonal relations, jealousy from colleagues, interpersonal conflicts and coping with sustained pressure to produce/perform (Lai et al., 2000).

In a survey done in Singapore among 2589 employees in 1990 , performance pressure and work-family conflicts were found to be the most important contributing sources of work stress among employees in the insurance industry (Chan et al., 2000). Other sources of stress within the insurance industry were related to possibilities of dealing with demanding or difficult clients, the employees' ability to survive in the insurance business and to achieve their career goals, time pressures and meeting deadlines, working continually to achieve targets, mental strain of work and work overload (Lai et al., 2000). Whilst the first two were perceived as a threat to the self-esteem, the latter ones were more associated with job demands. It seems that the overall perception of work stress by employees within the insurance industry was associated with work demands, lack of job security and the need to maintain a professional self (Lai et al., 2000).

Stress can be described as the stimulus or force that, if sufficiently strong, may cause tension in the individual who experiences it. The response is coping with or adapting to the stimulus, which may be either successful or unsuccessful. Stressful events lead to a strain reaction (Rowe, 2000). Strain (ill health) arises when individuals perceive themselves as unable to meet environmental demands (Taris, Schreurs \& Van Iersel-Van Silfout, 2001). The short-term effects of strain develop as an immediate reaction to specific working conditions (Demerouti, Bakker, Nachreiner \& Ebbinghaus, 2002).

Meyerson (1994) and Handy (1988) point out that an important consideration in terms of stress research should be that stress occurs in a particular context, since individuals differ in the meaning they attribute to stressful experiences. Therefore, the influence of the social construction of stressful experiences should be taken into account. According to Spielberger and Vagg (1999), the identification of major sources of stress at work offers a twofold benefit for both management and employees: firstly, by resulting in work environment changes that reduce stress and increase productivity; and secondly, by facilitating the development of effective interventions that could reduce the debilitating effects of occupational stress.

\section{Occupational stress}

According to Dewe, Cox and Ferguson (1993), stress is not a factor that resides in either the individual or the environment; rather, it is viewed as a dynamic cognitive state where the individual interaction with the environment can be described as an ongoing transaction. The term transaction implies 'that stress is neither in the person nor in the environment but in the relationship between the two' (Cooper, Dewe \& O'Driscoll, 2001: 12). Therefore, Siu (2002) argued that a stressful transaction occurs when persons both exert an impact on and respond to their environment. Following a transactional perspective, stress 
arises when the demands of a particular encounter (as appraised by the individual) is about to exceed the available resources, thereby threatening the well-being of (Lazarus, 1991) and bringing about change in the person's psychological and/or physiological condition in order to cope with the encounter (Cooper et al., 2001; Siu, 2002).

Work-related stress is considered to be the product of an imbalance between environmental demands and individual capabilities (Lazarus \& Folkman, 1984). However, most researchers adopt the fairly common practice of using the term 'stress' to describe either the external stimulus from the environment or the response of the individual, or sometimes both meanings simultaneously. To minimise semantic difficulties as well as theoretical confusion, this article will use the terms 'stressors' to refer to characteristics of the external environment (i.e. job characteristics and working conditions) and the term 'strain' to describe any response of the individual to these (i.e. physical and psychological ill health, and organisational commitment). The term 'stress' will, however, be used to indicate participants' responses to direct questions, for example, when enquiring whether they perceive a low, moderate or severe level of stress at work. Stressors do not inevitably lead to strain - a wide range of individual differences moderate this relationship.

Lu (1999) argued that stress has become one of the most serious health issues, a problem not just for individuals but also for employers. Research over the past three decades has shown that the experience of occupational stress is closely related to the health and safety of individuals and has definite implications for the well-being of organisations or institutions (Rees, 1995; Rees \& Redfern, 2000). A recent epidemiological survey conducted in the United Kingdom (Jones \& Hodgson, 1998) concluded that stress was the second most frequently reported condition of individuals who disclosed a work-related illness. Moreover, occupational stress has become one of the commonest reasons for medical retirement (Cooper \& Cartwright, 1994). It is evident, however, that in order for any organisation to address stress-related issues and implement effective interventions, it is necessary to diagnose job characteristics and working conditions that the workforce perceive to be stressful, investigate the outcomes of any stressors that are experienced and establish whether any particular sub-group of the working population is at greater risk (Kinman, 2001).

Studies have shown that occupational stressors may result in psychological, physical and behavioural stress reactions, such as burnout, depression and psychosomatic diseases (Houkes, Janssen, de Jonge \& Nijhuis, 2001; Lai et al., 2000). The link between unmanaged stress and its negative impact on health and well-being is well demonstrated in stress research and is linked to severe physical consequences, some of which may be fatal (Winefield, Gillispie, Stough, Dua \& Hapuararchchi, 2002). Occupational stress could also lead to disengagement, which in turn could affect the organisational commitment of employees (Schaufeli \& Bakker, 2004). Low organisational commitment could be interpreted as an escape from, compensation for, or protest against occupational stressors, which could result in absenteeism (Cohen, 1991; Sagie
1998). However, low organisational commitment could also develop when employees fail to cope with occupational stress.

Cartwright and Cooper (2002) developed a model which includes occupational stressors, strain (ill health) and organisational commitment (See Figure 1).

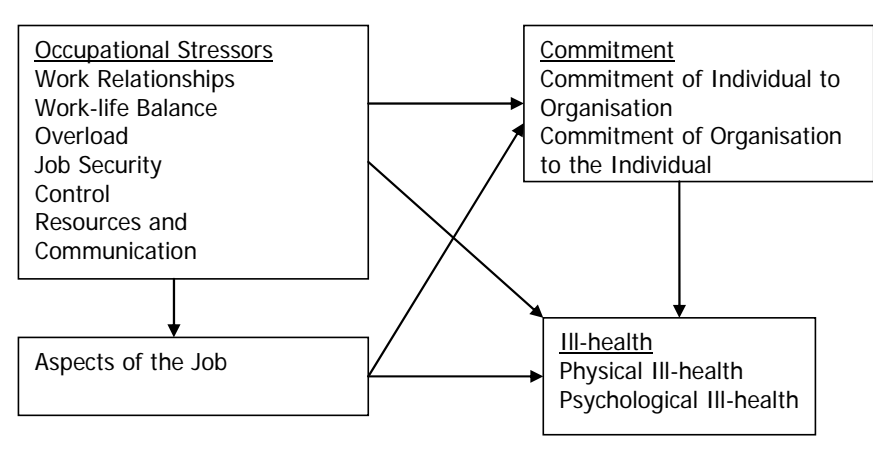

Figure 1: Model of occupational stress, commitment and ill health

As can be seen in Figure 1, seven occupational stressors are distinguished, namely work relationships (i.e., poor or unsupportive relationships with colleagues and/or superiors, isolation and unfair treatment), work-life imbalance (i.e., when work interferes with the personal and home life of individuals), overload (i.e., unmanageable work loads and time pressures), job security (i.e., fear of job loss or obsolescence), control (i.e., lack of influence in the way work is organised and performed), resources and communication (i.e., having the appropriate training, equipment and resources), pay and benefits (i.e., the financial rewards that work brings) and aspects of the job (i.e., sources of stress related to the fundamental nature of the job itself) are sources of stress. Commitment refers to an effect of stress. Poor health is an outcome of stress, which can be used to ascertain if workplace pressures have positive and motivating or negative and damaging effects. However, poor health may not necessarily be indicative of workplace stress (Cartwright \& Cooper, 2002).

Two approaches can be followed when defining organisational commitment (Blau \& Boal, 1987). In the first approach, commitment is seen as a behaviour during which the individual is viewed as committed to an organisation because it is too costly for him or her to leave. In the second approach the individual is committed to the organisation because of shared goals and the wish to maintain membership (Blau \& Boal, 1987:290). Organisational commitment is related to most of the physical and psychological outcomes among workers (Siu, 2002).

In their study on insurance agents, Lai et al. (2000) found that when gender, education, age and work experience in the organisation and the position are controlled, factors such as work pressures, uncertain job prospects and professionalism contributed significantly to the overall experience of work stress, with work demands standing out as the most 
important source of work stress. In this regard work experience in the organisation (i.e. length of service) tends to enhance job satisfaction (Lai et al., 2000), ultimately reducing the experience of stress. It may be due to a result of self-selection in that those employees who are not satisfied might have already left the organisation or even the profession. However, Preuss and Schaeke (1998) found no relationship between age, experience and level of perceived strain.

Research has demonstrated that work-related stressors can have a wide-ranging negative impact on the individual and the organisation. In terms of the current research, occupational stress of employees working in an insurance company in South Africa is studied. Not only is it important to establish reliable and valid methods of measurement of perceived stress, but based on the findings, the aim will be to understand stress as an organisational phenomenon so that it can be tackled at the organisation level.

\section{Aims of this study}

The aims of this study were to assess the internal consistency of the ASSET, to identify occupational stressors for employees in an insurance company and to assess the relationships between occupational stress, ill health and organisational commitment.

\section{Method}

\section{Research design}

A survey design was used to achieve the objectives of this study (Shaughnessy \& Zechmeister, 1997).

\section{Participants}

The total population of 1100 employees in an insurance company was targeted. A response rate of $56,5 \%$ was achieved, of which 613 responses $(98,55 \%)$ could be utilised. Descriptive information of the sample is given in Table 1.

The sample consisted mainly of English-speaking, married females $(57,26 \%)$ with a Grade 12 school qualification $(52,7 \%)$. The mean age of the participants was 35,5 years while the average length of service was 7,55 years.

\section{Measuring battery}

A biographical questionnaire was developed to gather information about the demographic characteristics of the participant. Information gathered included position, area, education, gender, marital status and language.
Tale 1: Characteristics of the participants

\begin{tabular}{|c|c|c|}
\hline Item & Category & $\begin{array}{c}\text { Frequency } \\
\text { (Percentage) }\end{array}$ \\
\hline \multirow[t]{6}{*}{ Education } & Grade 10 (Standard 8) & $48(8,35)$ \\
\hline & Grade 12 & $303(52,70)$ \\
\hline & Grade $12+$ Diploma & $133(23,13)$ \\
\hline & $\begin{array}{l}\text { Grade } 12+\text { Higher } \\
\text { Diploma or Degree }\end{array}$ & $68(11,83)$ \\
\hline & $\begin{array}{l}\text { Grade } 12+\text { Higher } \\
\text { Diploma or Degree } \\
\text { (Honours) }\end{array}$ & $16(2,78)$ \\
\hline & $\begin{array}{l}\text { Grade } 12+\text { Higher } \\
\text { Diploma or Degree } \\
\text { (Master's) }\end{array}$ & $7(1,22)$ \\
\hline \multirow[t]{7}{*}{ Role } & Clerical & $290(49,24)$ \\
\hline & Professional & $40(6,79)$ \\
\hline & $\begin{array}{l}\text { Management: Gr. 12- } \\
11\end{array}$ & $75(12,73)$ \\
\hline & Management: Gr.10-8 & $121(20,54)$ \\
\hline & Management: Gr. 7-5 & $59(10,02)$ \\
\hline & Management: Gr. 4-3 & $6(0,68)$ \\
\hline & Management: Gr. 2-1 & $0(0,00)$ \\
\hline \multirow[t]{2}{*}{ Gender } & Male & $262(42,74)$ \\
\hline & Female & $351(57,26)$ \\
\hline \multirow[t]{4}{*}{ Race } & Black & $67(10,95)$ \\
\hline & White & $281(45,92)$ \\
\hline & Coloured & $236(38,56)$ \\
\hline & Asian & $28(4,58)$ \\
\hline \multirow[t]{3}{*}{ Home Language } & Afrikaans & $208(34,04)$ \\
\hline & English & $339(55,48)$ \\
\hline & Other & $64(10,47)$ \\
\hline
\end{tabular}

The ASSET (which refers to An Organisational Stress Screening Tool) was developed by Cartwright and Cooper (2002) as an initial screening tool to help organisations assess the risk of occupational stress in their workforce. It measures potential exposure to stress in respect of a range of common workplace stressors. It also provides important information on current levels of physical health, psychological well-being and organisational commitment, and provides data to which the organisation can be compared. The ASSET is divided into four questionnaires. The first questionnaire (37 items) measures the individual's perception of his or her job. This subscale includes questions relating to eight potential sources of stress, namely: work relationship; work-life balance; overload; job security; control; resources and communication; job overall; and pay and benefits. The second questionnaire (9 items) measures the individual's attitude toward his or her 
organisation, and includes questions relating to perceived levels of commitment both from and to the organisation. The third questionnaire (19 items) focuses on the individual's health, aimed at specific outcomes of stress, and includes questions relating to both physical and psychological health. The fourth questionnaire (24 items) focuses on supplementary information, i.e. the background information, and includes questions relating to factors, which may affect stress. The first three questionnaires of the ASSET are scored on a six-point scale with 1 (strongly disagree) to 6 (strongly agree). The fourth questionnaire is scored on a four-point scale with 1 (never) to 4 (often).

The ASSET has an established set of norms from a database of responses from 20000 workers in the public and private sector organisations (non-higher education institutions) in the UK. Validity verification is still to be completed (Cartwright \& Cooper, 2002). Reliability is based on the Guttman split-half coefficient. All but two factors returned coefficients in excess of 0,70 , ranging from 0,60 to 0,91 (Cartwright \& Cooper, 2002). Johnson and Cooper (2003) found that the Psychological Well-being subscale has good convergent validity with an existing measure of psychiatric disorders, the General Health Questionnaire (GHQ - 12; Goldberg \& Williams, 1988). Tytherleigh (2003) used the ASSET as an outcome measure of job satisfaction in a nationwide study of occupational stress levels in 14 English higher education institutions. A series of Cronbach's alphas was carried out on each of the questions for the five ASSET subscales to identify the reliability of the ASSET questionnaire with these data. The results ranged from 0,64 to 0,94 , showing good reliability.

\section{Statistical analysis}

Descriptive statistics (means, standard deviations, skewness and kurtosis) were computed to describe the data. Cronbach alpha coefficients were used to assess internal consistency, of the scales (Clark \& Watson, 1995). Pearson productmoment correlation coefficients were used to specify the relationship between the variables. In terms of statistical significance, it was decided to set the value at a $95 \%$ confidence interval level ( $p \leq 0,01)$. Effect sizes (Steyn, 1999) were used to decide on the practical significance of the findings. A cut-off point of 0,30 (medium effect, Cohen, 1988) was set for the practical significance of correlation coefficients.

One-way analysis of variance (ANOVA) was used to determine the differences between the subgroups of the sample. Tukey's Standardised Range t-tests were used to determine the statistical significance of differences obtained during ANOVAs. Practical significance of the differences in means between two groups was computed (Cohen, 1988; Steyn, 1999). According to Cohen (1988), $0,10 \leq d \leq 0,50$ indicates a small effect; $0,50 \leq d \leq 0,80$ indicates a medium effect and $d \geq 0,80$ indicates a large effect. In terms of the current research, a cut-off point of 0,50 (medium effect) was set for the practical significance of the differences between group means. Standard multiple regression analysis was carried out to assess the contribution of the independent variables.

\section{Results}

The descriptive statistics of the ASSET items are reported in Table 2 .

Table 2 shows that acceptable Cronbach alpha coefficients varying from 0,66 to 0,89 were obtained, which compare reasonably well with the guideline of 0,70 (Nunnally \& Bernstein, 1994). Physical Health and Psychological Health (as measured by the ASSET) prove to be major outcomes of stress, as is reflected by the sten scores equal to and higher than 8 for these dimensions. On the physical level it seems as though one item is perceived as high levels of concern among the population, namely 'Muscular tension/aches/pains'. On the psychological level the following items were identified as major sources of concern: 'Feeling unable to cope', and 'Mood swings'. Reassuring is the fact that the population indicates that it does not revert to smoking and drinking in order to alleviate their stress.

The sten of 7 scored on the dimension Commitment from Organisation indicates that the employees experience feelings of trust and respect from the organisation resulting in their feeling that it is worth 'going the extra mile' for the organisation. On this dimension the outstanding item 'Proud of organisation' (sten of 10) indicates that individuals feel that their organisation is committed to them. The sten of 8 on the dimension of Commitment from the Individual indicates that the employees perceived their own levels of commitment towards the organisation as high. On this dimension the outstanding items 'Worthwhile to work hard for organisation' (sten of 8) and 'Committed to organisation' (sten of 8 ) indicate that the people forming the population are loyal and dedicated to the organisation and that they do their jobs to the best of their ability.

The major sources of occupational stressors in the total sample were job insecurity $($ sten $=9$ ) and pay and benefits $($ sten $=9)$. Under the Job Security dimension, one stressprovoking area is reflected by the item 'My skills may become redundant'. This indicates that members of the population may experience feelings that the niche they provide via their unique skills may become obsolete in the organisation. The high sten on 'Pay and benefits not as good as those of others in similar jobs' under the Pay and Benefits dimension is perceived by the population as a high stress-provoking area. In spite of the low score of the Job Characteristics dimension, two items give indications of high levels of stress perceived in these areas, namely 'Work performance are closely monitored', and 'Work is dull and repetitive'. The other dimensions and items with sten scores of 4-6 indicate average sources of stress. Although stress because of work relationships was average, two items showed relatively high scores, namely 'Colleagues are not pulling their weight' and 'Others take credit for what I have achieved.'

Table 2 shows that Physical Ill Health is practically significantly related to the following stressors: Overload, Job Characteristics and Control (all medium effects). Psychological Ill Health is practically significantly related to the following stressors: Work-Life Balance, Resources and Communication, Work Relationships, Overload, Job 
Characteristics, and Control (all medium effects). Commitment from the Organisation to the Individual is practically significantly (negatively) related to the following stressors: Resources and Communication, Work Relationships, Overload, and Control (all medium effects), and Job Characteristics (large effect). Individual Commitment to the Organisation is practically significantly (negatively) related to Job Characteristics and Control (both medium effects).

The differences for various biographical groups of employees in an insurance company were analysed in terms of perceived stress as reflected by the results of the ASSET. The difference in stress, organisational commitment and ill health of the different job categories are given in Table 3 .

Table 3 shows that the major differences in occupational stressors, organisational commitment and ill health concerned clerical employees (compared with employees on other job levels). Practically significant differences in the experience of stress because of resources and communication were found between clerical and management (grade 2-4 and grade 5-7) employees (large effect) and between clerical and professional employees (medium effect). Regarding the experience of stress because of work relationships, practically significant differences were found between clerical and management (grade 8-10 employees, medium effect) and clerical, professional and management (grade 2-4 and grade 5-7) employees (large effects). Practically significant differences in the experience of stress because of overload were found between clerical and professional employees (medium effect) and between clerical and management (grade 2-4) employees (large effect).

In the experience of stress because of job insecurity, practically significant differences (medium effect) were found between clerical employees on the one hand and grade 5-7 and grade 8-10 employees on the other hand. Practically significant differences in the experience of stress because of job characteristics were found between clerical and management (grade 11-12) employees (medium effect) and between clerical, professional and management (grade 2-10) employees (large effect). Regarding the experience of stress because of lack of control, practically significant difference were found between clerical, professional and management (grade 8-10) employees (medium effect) and between clerical and management (grade 2-7) employees (large effect). Practically significant differences in the experience of organisational commitment were found between management (grade 2-4) and professional and management (grade 8-12) employees (medium effect) and between management (grade 2-4) and clerical employees (large effect). Regarding the experience of physical and psychological ill health, practically significant differences were found between clerical, professional and management (grade 5-7) employees (medium effect) and between clerical and management (grade 2-4) employees (large effect).

The differences in stress, organisational commitment and ill health of employees in an insurance company in terms of their length of service in the company were also calculated. However, no statistically significant differences were found.
The results of multiple regression analyses with Individual Commitment to the Organisation, Physical Ill Health and Psychological Ill Health as dependent variable and occupational stressors as independent variables are reported in Table 4.

Table 4 shows that $16 \%$ of the variance in Individual Commitment to the Individual and $29 \%$ of the variance in Organisational Commitment to the Individual (as measured by the ASSET) are explained by occupational stress. However, only two stressors, namely Job Characteristics and Control showed statistically significant regression coefficients. Furthermore, $15 \%$ of the variance in Physical Ill Health (as measured by the ASSET) is explained by occupational stress. Two occupational stressors, namely Overload and Job Characteristics showed statistically significant regression coefficients and are therefore the best predictors of physical ill health. Lastly, $24 \%$ of the variance in Psychological Ill Health (as measured by the ASSET) is explained by occupational stress. Three occupational stressors, namely Work-life Balance, Overload and Job Characteristics obtained statistically significant regression coefficients and can be regarded as the best predictors of psychological (un)well-being.

\section{Discussion}

The aims of this study were to assess the internal consistency of the ASSET, to identify occupational stressors for employees in an insurance company and to assess the relationships between occupational stress, ill health and organisational commitment. The results showed that job insecurity as well as pay and benefits were the highest stressors in the insurance industry. Compared to an international norm, relatively high scores were obtained on physical and psychological ill health. Two stressors, namely job characteristics and control were statistically significant predictors of the two components of organisational commitment which were included in this study. Physical ill health was best predicted by two stressors, namely overload and job characteristics. Psychological unwell-being was best predicted by three stressors, namely work-life balance, overload and job characteristics.

The sten scores on the ASSET dimensions indicate that physical ill health and psychological ill health were major outcomes of stress for employees. More specifically, several physical (e.g. muscular tension/pains) and psychological symptoms (inability to cope and mood swings) were perceived to such an extent that they may have a detrimental effect on work performance, as is predicted by the study of Winefield et al. (2002). It was alarming to note that selfreported physical and psychological ill health in the insurance industry was high compared to the scores of an international norm. 


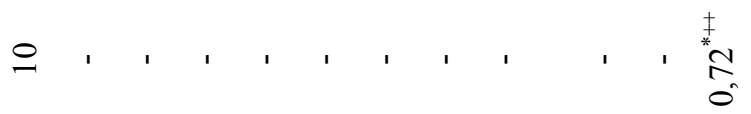

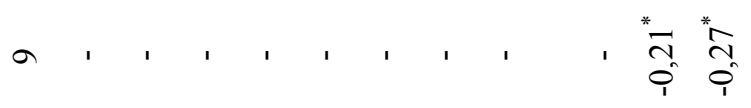

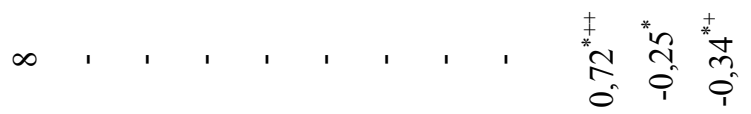

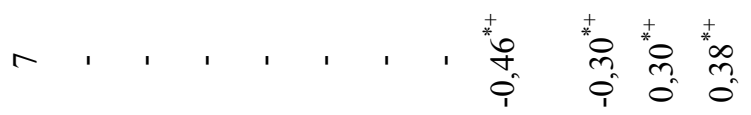

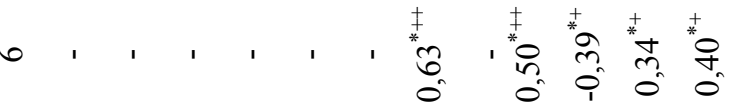

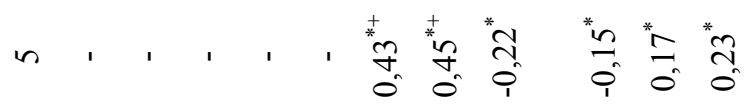

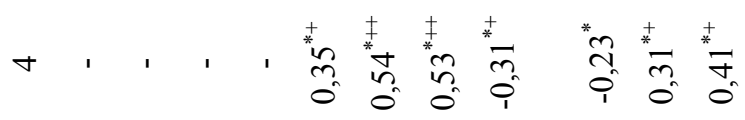

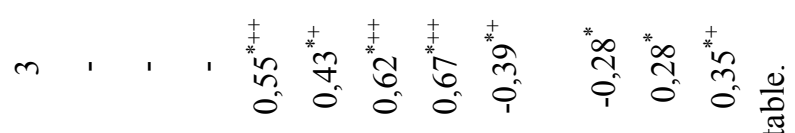

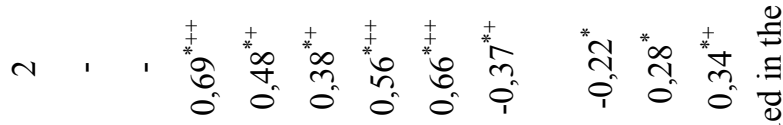

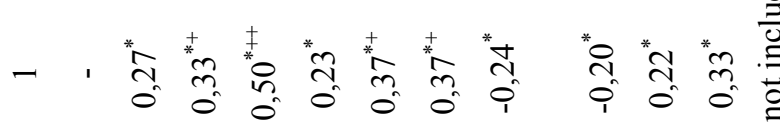

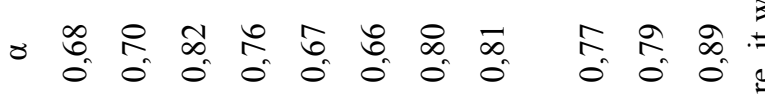

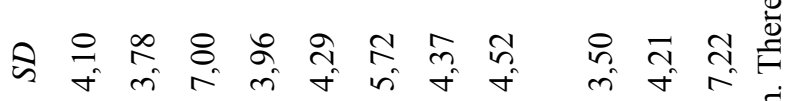

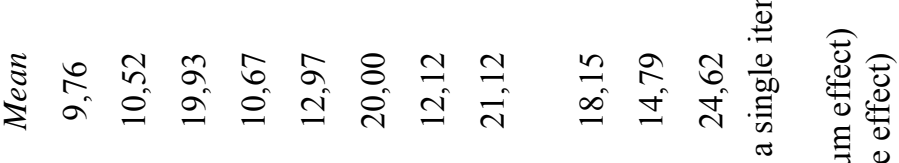

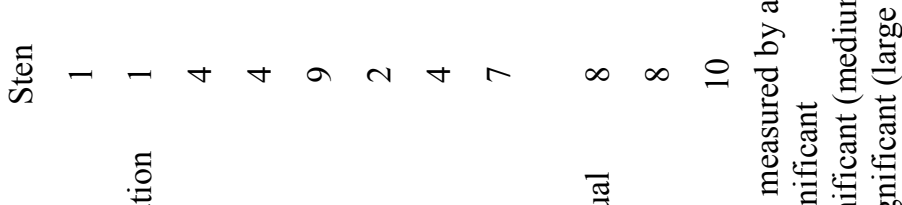

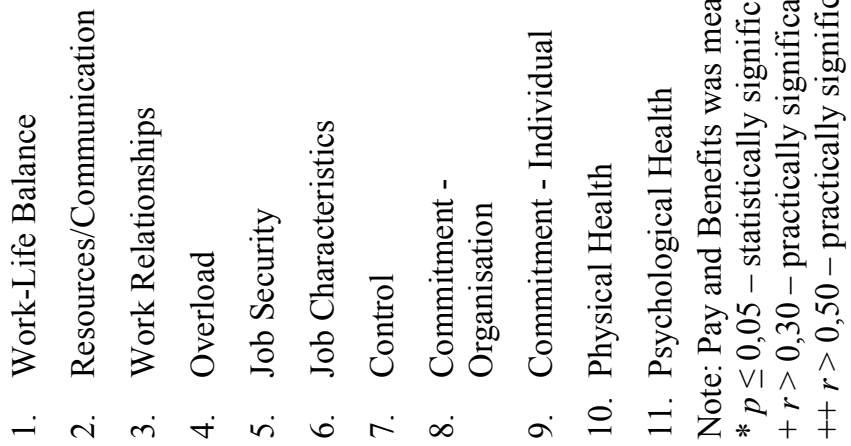


Table 3: ANOVAs - Differences in stress, organisational commitment and ill health of different job categories

\begin{tabular}{|c|c|c|c|c|c|c|c|c|}
\hline Item & Clerical & Professional & $\begin{array}{l}\text { Management: } \\
\text { Gr. 12-11 }\end{array}$ & $\begin{array}{l}\text { Management: } \\
\text { Gr. 10-8 }\end{array}$ & $\begin{array}{l}\text { Management: } \\
\text { Gr. 7-5 }\end{array}$ & $\begin{array}{l}\text { Management: } \\
\text { Gr. 2-4 }\end{array}$ & $\begin{array}{l}\text { Root } \\
\text { MSE }\end{array}$ & $p$ \\
\hline $\begin{array}{l}\text { Work-Life } \\
\text { Balance }\end{array}$ & 10,10 & 9,30 & 9,43 & 9,50 & 9,71 & 12,00 & 4,06 & 0,46 \\
\hline $\begin{array}{l}\text { Resources and } \\
\text { Communication }\end{array}$ & $11,45^{\mathrm{a}}$ & $8,85^{\mathrm{b}}$ & 10,96 & 10,01 & $8,34^{\mathrm{c}}$ & $5,25^{\mathrm{c}}$ & 3,62 & $0,01^{*}$ \\
\hline $\begin{array}{l}\text { Work } \\
\text { Relationships }\end{array}$ & $22,14^{\mathrm{a}}$ & $16,08^{\mathrm{c}}$ & 20,48 & $18,19^{\mathrm{b}}$ & $15,95^{\mathrm{c}}$ & $9,25^{\mathrm{c}}$ & 6,58 & $0,01^{*}$ \\
\hline Overload & $11,50^{\mathrm{a}}$ & $9,38^{\mathrm{b}}$ & 10,51 & 9,79 & 10,44 & $6,75^{\mathrm{c}}$ & 3,91 & $0,01^{*}$ \\
\hline Job Security & $14,06^{\mathrm{a}}$ & 12,00 & 12,79 & $11,69^{\mathrm{b}}$ & $11,22^{\mathrm{b}}$ & 12,50 & 4,17 & $0,01 *$ \\
\hline $\begin{array}{l}\text { Job } \\
\text { Characteristics }\end{array}$ & $22,42^{\mathrm{a}}$ & $16,48^{\mathrm{c}}$ & $19,67^{\mathrm{b}}$ & $18,15^{\mathrm{c}}$ & $15,88^{\mathrm{c}}$ & $10,75^{\mathrm{c}}$ & 5,11 & $0,01^{*}$ \\
\hline Control & $13,40^{\mathrm{a}}$ & $10,43^{\mathrm{b}}$ & 11,99 & $11,00^{\mathrm{b}}$ & $9,83^{\mathrm{c}}$ & $5,75^{\mathrm{c}}$ & 4,13 & $0,01 *$ \\
\hline $\begin{array}{l}\text { Commitment } \\
\text { from Individual }\end{array}$ & $20,17^{\mathrm{c}}$ & $21,90^{\mathrm{b}}$ & $21,53^{\mathrm{b}}$ & $21,31^{b}$ & 24,22 & $24,75^{\mathrm{a}}$ & 4,34 & $0,01^{*}$ \\
\hline $\begin{array}{l}\text { Commitment } \\
\text { from } \\
\text { Organisation }\end{array}$ & $17,45^{\mathrm{c}}$ & $18,68^{b}$ & $18,51^{\mathrm{b}}$ & $18,41^{\mathrm{b}}$ & 20,20 & $21,00^{\mathrm{a}}$ & 3,36 & $0,01^{*}$ \\
\hline Physical Health & $15,60^{\mathrm{a}}$ & $13,33^{\mathrm{b}}$ & 15,16 & 14,06 & $12,85^{\mathrm{b}}$ & $9,50^{\mathrm{c}}$ & 4,10 & $0,01^{*}$ \\
\hline $\begin{array}{l}\text { Psychological } \\
\text { Health }\end{array}$ & $26,08^{\mathrm{a}}$ & $22,50^{\mathrm{b}}$ & 24,85 & 22,98 & $21,76^{\mathrm{b}}$ & $14,25^{\mathrm{c}}$ & 7,02 & $0,01 *$ \\
\hline
\end{tabular}

* Statistically significant difference: $p<0,01$

a Practically significant differences from group (in row) where b (medium effect, $d \geq 0,5$ ) or c (large effect, $d \geq 0,8)$ are indicated

The scores of both individual commitment to the organisation and the commitment of the organisation to the individual were high compared to the norm. Employees in an insurance company displayed feelings of trust, respect and pride towards the organisation, indicating an understanding that the organisation is committed to the employees. The employees perceive their own levels of commitment towards the organisation as high, indicating that they are loyal and dedicated to the organisation and that they do their work to the best of their ability.

Compared to the international norm (Cartwright \& Cooper, 2002), two occupational stressors were high, namely job insecurity and pay and benefits. Job insecurity refers to insecurity about the permanence of the job, possible changes to the jobs and the possibility that skills will become redundant in the future. Stress because of job insecurity was also high for this sample compared to other South African organisations (see Coetzee \& Rothmann, 2005; Jackson \& Rothmann, 2005). Employees might feel stressed because they might loose their jobs and because they feel uncertain about the future. It should be noted that stress because of constant changes in the organisation was high. Lindström, Leino, Seitsamo and Tordtila (1997) also found that employees in insurance companies experience high job insecurity. Pay and benefits, refer to stress because of perceptions that pay and benefits were not as good as those of others in similar jobs.

Occupational stressors which were found to be average compared to the norm (Cartwright \& Cooper, 2002), include work relationships and overload. Regarding work relationships, lack of support from the manager and colleagues, colleagues who are not pulling their weight and others taken credit for what someone has achieved were significant stressors. Regarding overload, unrealistic deadlines, unmanageable workloads and not having enough time to properly do the job were significant stressors. These findings are in line with the results of Lai et al. (2000).

It is interesting to note that in this study the employees did not perceive work-life balance, and resources and communication as highly stressful. Some facets of these dimensions that participants did indicate as stressors, include performance management and the characteristics of the actual job (i.e. work is dull and repetitive). These stressors, if not attended to, may result in corrosion of organisational commitment in the longer run.

Regarding the differences in stress levels based on biographical characteristics of the population, clerical employees scored significantly higher stressors related to resources and communication, work relationships, overload, job characteristics, and control. Clerical employees also showed significantly higher physical and psychological ill health compared with professional and some managerial employees. Clerical employees scored significantly higher on stress because of job insecurity than management staff. Management staff on higher levels (grade 2-4) scored significantly higher on organisational commitment than lower level managers, clerical, and professional staff. 
Table 4: Standard multiple regression analyses

\begin{tabular}{|c|c|c|c|c|c|c|c|c|c|}
\hline \multirow[t]{2}{*}{ Variable } & & \multicolumn{2}{|c|}{ Unstandardised Coefficients } & \multirow{2}{*}{$\begin{array}{c}\text { Standardised Coefficients } \\
\text { Beta }\end{array}$} & \multirow[t]{2}{*}{$t$} & \multirow[t]{2}{*}{$p$} & \multirow[t]{2}{*}{$F$} & \multirow[t]{2}{*}{$R^{2}$} & \multirow[t]{2}{*}{$R$} \\
\hline & & B & SE & & & & & & \\
\hline \multicolumn{2}{|c|}{ Individual Commitment to the Organisation } & & & & & & $16,85^{*}$ & 0,16 & 0,40 \\
\hline & Intercept & 22,97 & 0,55 & & 42,070 & 0,00 & & & \\
\hline & Work-Life Balance & $-0,04$ & 0,04 & $-0,05$ & $-1,14$ & 0,26 & & & \\
\hline & Resources/Communication & 0,06 & 0,05 & 0,07 & 1,18 & 0,24 & & & \\
\hline & Work Relationships & $-0,03$ & 0,03 & $-0,05$ & $-0,89$ & 0,37 & & & \\
\hline & Overload & 0,01 & 0,05 & 0,01 & 0,16 & 0,87 & & & \\
\hline & Job Security & 0,04 & 0,04 & 0,05 & 1,14 & 0,26 & & & \\
\hline & Job Characteristics & $-0,20$ & 0,03 & $-0,33$ & $-6,14$ & $0,00^{*}$ & & & \\
\hline & Control & $-0,09$ & 0,05 & $-0,12$ & $-1,97$ & $0,05^{*}$ & & & \\
\hline \multicolumn{2}{|c|}{ Organisational Commitment to the Individual } & & & & & & $34,66^{*}$ & 0,29 & 0,54 \\
\hline & Intercept & 29,50 & 0,65 & & 45,26 & 0,00 & & & \\
\hline & Work-Life Balance & $-0,04$ & 0,04 & $-0,04$ & $-0,87$ & 0,38 & & & \\
\hline & Resources/Communication & $-0,05$ & 0,06 & $-0,04$ & $-0,78$ & 0,44 & & & \\
\hline & Work Relationships & $-0,01$ & 0,04 & $-0,02$ & $-0,39$ & 0,70 & & & \\
\hline & Overload & 0,03 & 0,05 & 0,02 & 0,48 & 0,63 & & & \\
\hline & Job Security & 0,06 & 0,04 & 0,05 & 1,34 & 0,18 & & & \\
\hline & Job Characteristics & $-0,27$ & 0,04 & $-0,34$ & $-6,85$ & $0,00^{*}$ & & & \\
\hline & Control & $-0,24$ & 0,06 & $-0,23$ & $-4,30$ & $0,00^{*}$ & & & \\
\hline \multicolumn{2}{|c|}{ Physical Ill Health } & & & & & & $14,80^{*}$ & 0,15 & 0,38 \\
\hline & Intercept & 8,88 & 0,67 & & 130,33 & 0,00 & & & \\
\hline & Work-Life Balance & 0,06 & 0,05 & 0,06 & 10,25 & 0,21 & & & \\
\hline & Resources/Communication & 0,07 & 0,06 & 0,06 & 10,13 & 0,26 & & & \\
\hline & Work Relationships & 0,01 & 0,04 & 0,01 & 0,17 & 0,86 & & & \\
\hline & Overload & 0,14 & 0,06 & 0,13 & 20,61 & $0,01 *$ & & & \\
\hline & Job Security & $-0,02$ & 0,04 & $-0,02$ & $-0,52$ & 0,61 & & & \\
\hline & Job Characteristics & 0,13 & 0,04 & 0,18 & 30,27 & $0,00^{*}$ & & & \\
\hline & Control & 0,05 & 0,06 & 0,06 & 0,93 & 0,35 & & & \\
\hline \multicolumn{2}{|c|}{ Psychological Ill Health } & & & & & & $26,84^{*}$ & 0,24 & 0,49 \\
\hline & Intercept & 7,45 & 0,74 & & 10,05 & 0,00 & & & \\
\hline & Work-Life Balance & 0,15 & 0,05 & 0,13 & 3,00 & $0,00^{*}$ & & & \\
\hline & Resources/Communication & 0,12 & 0,07 & 0,09 & 1,70 & 0,09 & & & \\
\hline & Work Relationships & $-0,02$ & 0,04 & $-0,03$ & $-0,43$ & 0,67 & & & \\
\hline & Overload & 0,25 & 0,06 & 0,20 & 4,08 & $0,00^{*}$ & & & \\
\hline & Job Security & $-0,04$ & 0,05 & $-0,03$ & $-0,73$ & 0,47 & & & \\
\hline & Job Characteristics & 0,14 & 0,04 & 0,16 & 3,17 & $0,00^{*}$ & & & \\
\hline & Control & 0,10 & 0,06 & 0,09 & 1,64 & 0,10 & & & \\
\hline
\end{tabular}

* $p<0,05$

Low organisational commitment of employees in the insurance industry was best predicted by two stressors, namely job characteristics (e.g. expecting to do the same job in the future, constant changes in the organisation, dealing with difficult clients, doing a dull and repetitive job, and not enjoying the job) and control (e.g. having little control, not being involved in decisions, and little influence over performance targets). The Job Demand-Control Model
(Karasek \& Theorell, 1990) explains occupational stress and the effects thereof in terms of the role of job demands on the one hand, and low autonomy and decision latitude on the other hand. Applied to our findings, low organisational commitment could be regarded as an effect of occupational stress, as well as a form of withdrawal behaviour (Cohen, 1991; Sagie, 1998; Schaufeli \& Bakker, 2004), which results when employees experience stressful job characteristics, but 
they also experience limited control to do something about it.

Physical ill health was best predicted by job characteristics and overload. Therefore, it seems that performing a job which is inherently stressful and at the same time experiencing that the work load and time pressure are unmanageable, result in physical ill health symptoms. stressful job characteristics and overload. Stressful job characteristics and overload were not only statistically significant predictors of physical ill health, but also of psychological unwell-being. In addition, stress because of work-life balance (i.e., when work interferes with the personal and home life of employees) also contributed significantly to explaining psychological unwell-being. These results confirm the findings of Lai et al. (2000) that employees in the insurance industry experience occupational stress because of pressures such as demanding clients, time pressures and meeting deadlines, working continually to achieve targets, and work overload.

It can be concluded from this study that job characteristics of employees in the insurance industry play a role in low organisational commitment, but also in physical ill health and psychological unwell-being. However, organisational commitment decreases further when employees experience stress about control, while physical ill health symptoms increase when employees experience stress about workload. Furthermore, psychological unwell-being symptoms increase when stress about workload and work-life balance increase.

This study had various limitations. First, an availability sample of employees in one insurance company was used. Therefore, it is not possible to generalise the findings to all insurance companies. Future studies should consider extending the sample to include employees of other insurance companies in South Africa. Second, a crosssectional survey design was used, which makes it impossible to prove causal relationships between occupational stressors on the one hand, and ill health and organisational commitment on the other hand. Future studies of occupational stress in the insurance industry should make use of longitudinal designs, which will make it possible to analyse cause and effect relationships. Lastly, this study relied solely on self-report measures of occupational stress, ill health and organisational commitment. Future studies should link subjective experiences of employees to a range of well-being indicators and effects (e.g. sickness absence, job performance, and medical fund utilisation).

\section{Recommendations}

Within the present study, physical and psychological health were found to be the major outcomes of perceived stressors. The organisation is therefore advised to take note of the impact of stressors such as job characteristics, workload and work-home balance in order to protect both the employee and the organisation against the negative effects of occupational stress. If especially the physical and psychological stressors are allowed to continue unattended, the organisation can expect to encounter negative costs associated with continued, elevated levels of stress, such as burnout, absenteeism, employee turnover and lowered levels of service.

Interventions to manage occupational stress in the insurance company are necessary. Interventions may be directed at either the work situation or the coping capacity of the employees (Kompier \& Kristensen, 2001). Work-oriented interventions aim to improve the fit between an individual and the workplace. Worker-oriented interventions aim at teaching employees to deal more effectively with experienced stress, or to modify their appraisal of a stressful situation, so that the perceived stress threats are reduced.

Secondary-level interventions can be implemented to prevent employees who are already showing signs of stress from getting sick and to increase their coping capacity. Examples include cognitive structuring, time management, conflict resolution techniques and coping strategies. Tertiary-level interventions are concerned with the rehabilitation of individuals who have suffered ill health or reduced well-being as a result of (ill) health in the workplace.

\section{References}

Blau, G.J. \& Boal, K.B. 1987. 'Conceptualizing how job involvement and organizational commitment affect turnover \& absenteeism', Academy of Management Review, 12:288300 .

Cartwright, S. \& Cooper, C.L. 2002. ASSET: An organisational stress screening tool - The management guide. Manchester: RCL Ltd.

Chan, K.B. 2002. 'Coping with work stress, work satisfaction, and social support: An interpretive study of life insurance agents', Asian Journal of Social Science, 30:657685.

Chan, K.B., Lai, G., Ko, Y.C. \& Boey, K.W. 2000. 'Work stress among six professional groups: The Singapore experience', Social Science \& Medicine, 50:1415-1432.

Clark, L.A. \& Watson, D. 1995. 'Constructing validity: Basic issues in objective scale development', Psychological Assessment, 7:309-319.

Coetzee, S.E. \& Rothmann, S. 2005. 'Occupational stress in a higher education institution in South Africa', South African Journal of Industrial Psychology, 31(1):47-54.

Cohen, A. 1991. 'Career stage as a moderator of the relationships between organizational commitment and its outcomes: A meta-analysis', Journal of Occupational Psychology, 64:253-268.

Cohen, J. 1988. Statistical power analysis for the behavioral sciences. Revised edition. Orlando, FL: Academic Press.

Cooper, C.L. \& Cartwright, S. 1994. 'Stress management interventions in the workplace: Stress counseling and stress 
audits', British Journal of Guidance and Counselling, 22: $65-73$.

Cooper, C.L., Dewe, P.J. \& O'Driscoll, M.P. 2001. Organisational stress: A review and critique of theory, research, and applications. Thousand Oaks, CA: Sage Publications.

Demerouti, E., Bakker, A.B., Nachreiner, F. \& Ebbinghaus, M. 2002. 'From mental strain to burnout', European Journal of Work and Organisational Psychology, 11(4):423-441.

Dewe, P.J., Cox, T. \& Ferguson, E. 1993. 'Individual strategies for coping with stress and work: A review', Work and Stress, 7:5-15.

Goldberg, D.P. \& Williams, P. 1988. A user's guide to the GHQ. London: NFER, Nelson.

Handy, J.A. 1988. 'Theoretical and methodological problems within occupational stress and burnout research', Human Relations, 41:351-369.

Holmes, T.H. \& Rahe, R.H. 1967. 'The social readjustment rating scale', Journal of Psychosomatic Research, 11:213218.

Houkes, I., Janssen, P.P.M., De Jonge, J. \& Nijhuis, F.J.N. 2001. 'Specific relationships between work characteristics and intrinsic work motivation, burnout and turnover intention: A multi-sample analysis', European Journal of Work and Organizational Psychology, 10:1-23.

Jackson, L.T.B. \& Rothmann, S. 2005. 'Occupational stress, ill-health and organisational commitment of educators in the North West Provinc'. Paper presented at the $8^{\text {th }}$ Annual Conference of the Society for Industrial and Organisational Psychology, Pretoria.

Johnson, S. \& Cooper, C. 2003. 'The construct validity of the ASSET stress measure'. Unpublished manuscript made available by authors.

Jones, J.R. \& Hodgson, J.T. 1998. Self-reported workrelated illness in 1995: Results from a household survey. London: HSE Books.

Karasek, R.A. \& Theorell, T. 1990. Healthy work: Stress, productivity and the reconstruction of working life. New York: Wiley.

Kinman, G. 2001. 'Pressure points: A review of stressors and strains in UK academics', Educational Psychology, 21:474-492.

Kompier, A.J. \& Kristensen, T.S. 2001. 'Organizational work stress interventions in a theoretical, methodological and practical context'. In Dunham, J. (Ed.). Stress in the workplace: Past, present and future. London: Whurr Publishers, pp. 19-33.

Lai, G., Chan, K.B., Ko, Y.C. \& Boey, K.W. 2000. 'Institutional context and stress appraisal: The experience of life insurance agents in Singapore', Journal of Asian \& African Studies, 35:209-228.

Lazarus, R.S. 1991. 'Psychological stress in the workplace', Journal of Social Behaviour and Personality, 6:1-13.

Lazarus, R.S. \& Folkman, S. 1984. Stress, appraisal, and coping. New York: Springer.

Lindström, K., Leino, T., Seitsamo, J. \& Tordtila, L. 1997. 'A longitudinal study of work characteristics and health complaints among insurance employees in VTD work', International Journal of Human-Computer Interaction, 9:343-368.

Lu, L. 1999. 'Work, motivation, job stress and employee's well-being', Journal of Applied Management Studies, 8:6172 .

Meyerson, D.E. 1994. 'Interpretations of stress in institutions: The cultural production of ambiguity and burnout', Administrative Science Quarterly, 39:628-653.

Nunnally, J.C. \& Bernstein, I.H. 1994. Psychometric theory ( $3^{\text {rd }}$ edition). New York: McGraw-Hill.

Preuss, G. \& Schaeke, G. 1998. 'Firefighters exposed to psychomental stress and hazardous work situations'. Poster presented at the Work, Health and Stress Conference, Institut für Arbeitsmedizin der Freien Universität, Berlin, Germany.

Rees, D.W. 1995. 'Work-related stress in health service employees', Journal of Managerial Psychology, 10:4-11.

Rees, C.J. \& Redfern, D. 2000. 'Recognizing the perceived causes of stress: A training and development perspective', Industrial and Commercial Training, 32:120-127.

Rowe, M. 2000. 'Skills training in the long-term management of stress and occupational burnout', Current Psychology, 19:215-229.

Sagie, A. 1998. 'Employee absenteeism, organizational commitment, and job satisfaction: Another look', Journal of Vocational Behavior, 52:156-171.

Schaufeli, W.B. \& Bakker, A. B. 2004. 'Job demands, job resources, and their relationship with burnout and engagement: A multi-sample study', Journal of Organizational Behaviour, 25:1-23.

Shaughnessy, J.J. \& Zechmeister, E.B. 1997. Research methods in psychology ( $4^{\text {th }}$ edition). New York: McGrawHill.

Siu, O.L. 2002. 'Occupational stressors and well-being among Chinese employees: The role of organizational commitment', Applied Psychology: An International Review, 5:527-544. 
Spielberger, C.D. \& Vagg, P.R. 1999. Job stress survey:

Professional manual. Odessa, FL: Psychological Assessment Resources.

Steyn, H.S. 1999. Praktiese beduidendheid: Die gebruik van effekgroottes. [Practical significance: The use of effect sizes.] Wetenskaplike bydraes - Reeks B: Natuurwetenskappe Nr. 117. Potchefstroom: PU vir CHO.

Taris, T.W., Schreurs, P.J.G. \& Van Iersel-Van Silfhout, I.J. 2001. 'Job stress, job strain, and psychological withdrawal among Dutch university staff: Towards a dual-process model for the effects of occupational stress', Work \& Stress, 15: 283-296.

Tytherleigh, M.V. 2003. 'What employers may learn form English higher education institutions: A fortigenic approach to occupational stress', SA Journal of Industrial Psychology, 29(4):101-106.

Winefield, A.H., Gillispie, N., Stough, C., Dua, J. \& Hapuararchchi, J. 2002. Occupational stress in universities: A national survey. Melbourne: National Tertiary Education Union.

\section{Author Note}

This material is based upon work supported by the National Research Foundation under Grant number 2053344. 